\title{
A Cost-Analysis of Computed Radiography and Picture Archiving and Communication Systems in Portable Radiography
}

\author{
Walter Huda, Janice C. Honeyman, Meryll M. Frost, and Edward V. Staab
}

\begin{abstract}
A total of $\mathbf{4 0 , 0 0 0}$ portable examinations are performed each year at Shands Hospital (Gainesville, FL), a 570bed teaching hospital. Radiographs are obtained using a screen-film combination with the films digitized for transmission to displays in four intensive care units. A cost-analysis of replacing screen-film with computed radiography (CR) integrated into a filmless picture archiving and communication system (PACS) network was performed. Equipment requirements included two CR units, three high-resolution dual monitor displays, and an archive to store 3 months of image data. The capital costs were amortized over a 5-year period. Capital and operating costs of the proposed expansion to the existing PACS network, together with anticipated cost savings, were determined. The maximum data transfer rate for portable examinations was 150 MByte per hour and approximately 400 GByte of image data are generated each year. These figures were used to determine the hardware requirements for handling the acquisition, transfer, and display of the images. Annual costs of the proposed expansion were about $\$ 220,000$. Cost savings were achieved by elimination of film, including its handling by technologists / library clerks, and amounted to about $\$ 200,000$ per year.

Copyright 1996 by W.B. Saunders Company
\end{abstract}

KEY WORDS: computed radiography (CR), picture archiving and communication system (PACS), costanalysis.

$\mathbf{C}$ OMPUTED radiography (CR) was introduced into clinical practice over a decade ago $^{1}$ with a potential of filmless digital radiology. Major advantages of CR over conventional screen-film combinations include a wide dynamic range $\left(10^{4}: 1\right)$ and the availability of image processing. ${ }^{2}$ Limitations of CR compared with screen-film systems include an inferior spatial resolution $(\sim 3 \mathrm{lp} / \mathrm{mm})$ and higher image noise when exposed to same radiation doses. ${ }^{3}$ The auto-ranging feature of CR guarantees consistent film density irrespective of the radiation exposure, and has resulted in CR being widely accepted for performing portable examinations. ${ }^{4,5} \mathrm{CR}$ also permits the printing of multiple images and access to digital image data that can eliminate the problem of lost films.

A number of radiology departments developing picture archiving and communication systems (PACS) have used CR to perform most of their radiographic procedures. ${ }^{6.7}$ From a technical perspective CR clearly can replace screenfilm systems. However, it is also important to address the economic impact of introducing new technology. ${ }^{89}$ Tucker et al ${ }^{10}$ described an intensive care unit (ICU) PACS system developed at the University of Alabama (Birmingham), for which an analysis was performed indicating that the cost of the PACS was offset by the savings realized by the elimination of film. In this study, the financial implications of introducing a CR/PACS network to perform portable examinations in a 570-bed teaching hospital were investigated.

\section{MATERIALS AND METHODS}

\section{Clinical Workload}

Approximately 40,000 portable examinations are performed at the 570-bed Shands Hospital (Gainesville, FL) each year. Two thirds of these are taken in six ICUs. About $80 \%$ of portable studies are chest examinations $(70 \%$ adult with the remaining $30 \%$ pediatric). Of the $20 \%$ nonchest portable examinations, most are abdominal $(\sim 15 \%)$, with the remaining $5 \%$ consisting of musculoskeletal and neuroradiology studies.

The portable examination workload distribution obtained from 5 consecutive working days for each ICU at Shands Hospital is shown in Fig 1. The corresponding data for all non-ICU portable examinations are shown in Fig 2. The distinction between the two types of portable examinations (ICU and non-ICU) is made because although all imaging will be performed with $\mathrm{CR}$ and will add to the network load, only the ICU portables will be sent to workstations in the corresponding ICUs. Non-ICU images will be displayed only in the radiology department for diagnostic interpretation. During this 5-day period, 700 examinations were performed generating 762 films (ie, 1.09 films per patient examination). Each film is taken to correspond to an uncompressed image content of 8 MBytes ( 2 KByte $\times 2$ KByte $\times 2$ Byte per pixel).

The hourly acquisition rate for all portable examinations

From the Department of Radiology, College of Medicine, University of Florida, Gainesville.

Address reprint requests to Janice C. Honeyman, $P h D$, University of Florida, Department of Radiology, PO Box 100374, College of Medicine, 1600 SW Archer Rd, Gainesville, FL 32610-0374.

Copyright 01996 by W.B. Saunders Company

0897-1889/96/0901-0003\$3.00/0 

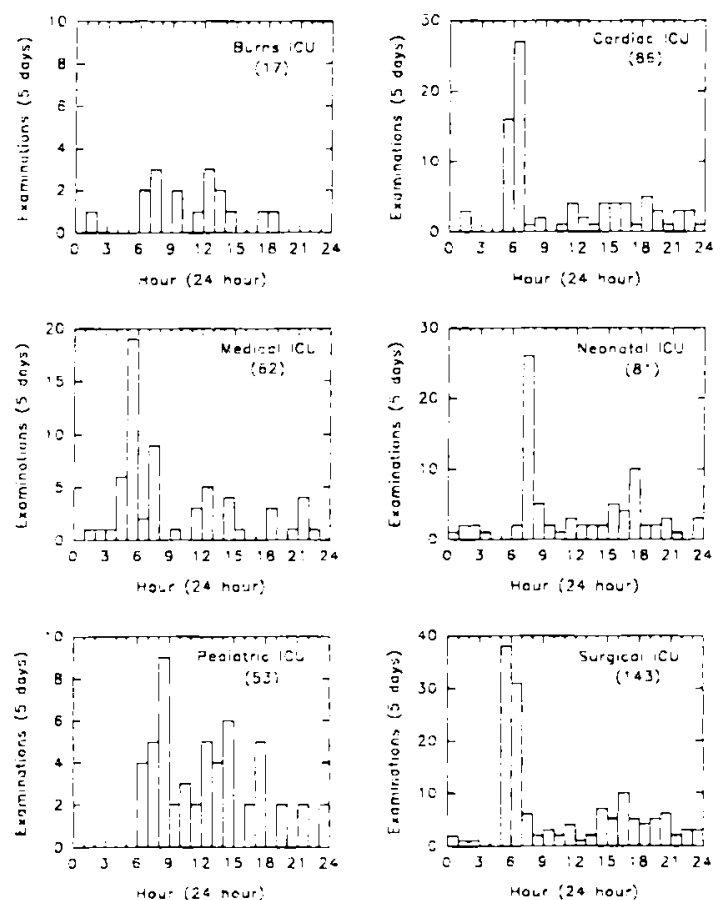

Fig 1. Portable chest examinations versus time of day for all six ICUs (summed data for 5 working days).

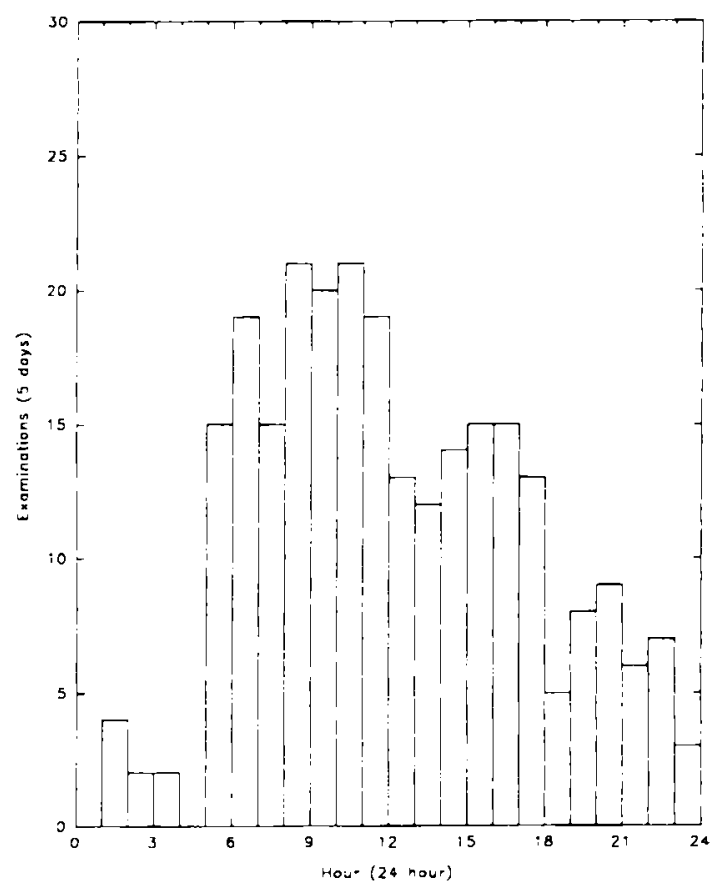

Fig 2. Non-ICU portable examinations (258; abdomen. musculoskeletal, head, miscellaneous chest, etc) versus time of day (summed data for 5 working days).

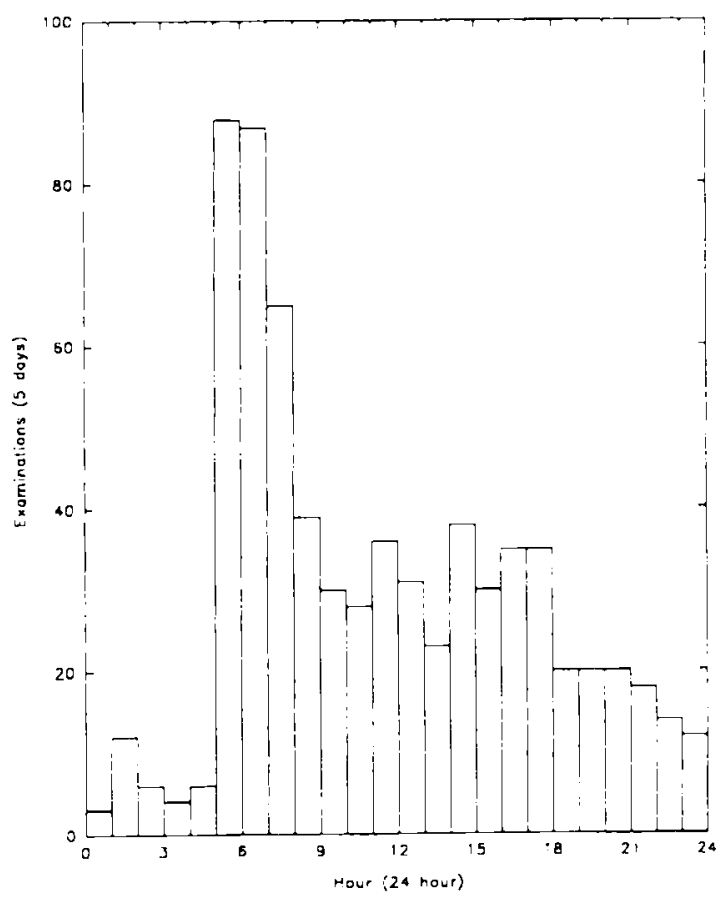

Fig 3. Summary of all portable examinations $(700)$ versus time of day (summed data for 5 working days).

is shown in Fig 3. which defines the data transfer and storage requirements of a dedicated image archive. The maximum image acquisition rate for all portables examinations is only about 150 MByte per hour. An archive capable of storing images for a 3 -month period would require a capacity of approximately 100 Gbyte.

\section{PACS Network Design}

The CR/PACS network designed to handle the portable examination workload at Shands Hospital is shown in Fig 4. Four ICUs currently use dual-monitor clinical review system (CRS) displays (Dupont Inc. Wilmington, DE) that permit images to be reviewed by the ICU clinicians. In the proposed extension of the current PACS network, all acquired portable images would be sent to one of three high-resolution displays (dual-monitor) in the Radiology Department for diagnostic interpretation with no production of hard-copy CR images. Local storage requirements for these diagnostic stations, each holding 1 week of studies, would be 10 GBvte and 4 GByte for the Adult and Pediatric reading areas. respectively. Images would be stored on the archive in full resolution for 3 months.

Two CR systems were allotted to provide a backup capability for system preventative maintenance and breakdowns. The CRs will need to perform up to 140 examinations each day and handle an early morning peak examination rate of 20 per hour. An estimated 25 imaging plates would be needed to satisfy the anticipated clinical workload $\left(1010^{\prime \prime} \times 12^{\prime \prime}\right.$ and $\left.1514^{\prime \prime} \times 17^{\prime \prime}\right)$ 


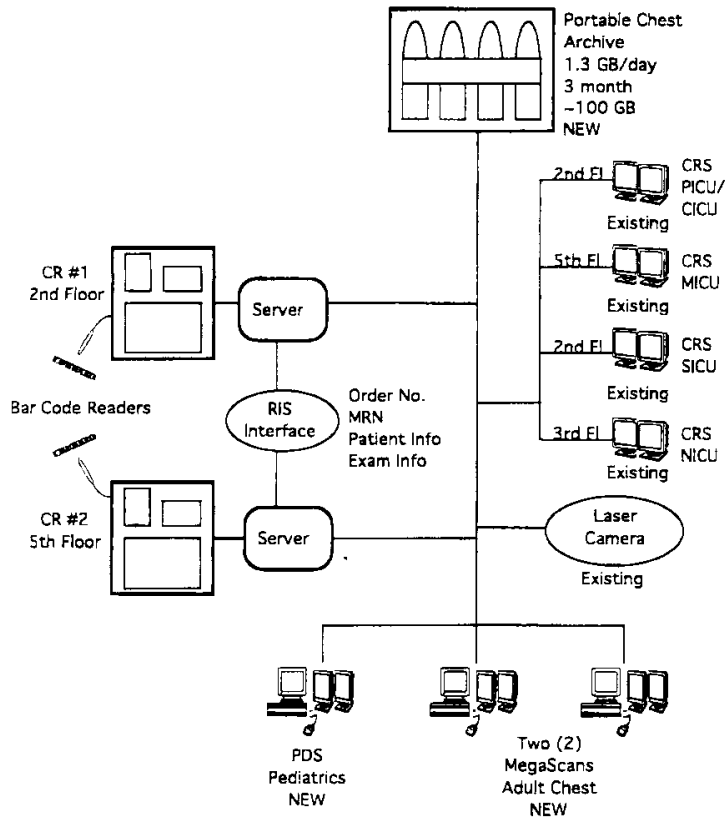

Fig 4. Schematic outline of the proposed CR/PACS network for performing all portable examinations at Shands Hospital.

\section{Cost Assessment}

Obtaining definitive costs and savings of the proposed CR/PACS network is difficult. The approach adopted in this study was to use nominal list prices for all equipment and supplies. This provides a consistent framework for comparing expenditures with cost savings. The potential reduction in staff requirements (technologists and file room clerks) was estimated taking into account the current staffing levels and anticipated increases in efficiency of the proposed CR/PACS network. Nine personnel including radiologists, scientists, technologists, film file clerks, and administrators were asked to estimate the personnel savings that might be realized through eliminating film and film handling. Although the costing methodology used in this study was not sophisticated, the data provided identify the key financial issues associated with proposed installation of this CR/PACS network.

\section{RESULTS}

\section{Capital and Operating Costs}

The capital costs required to install the proposed CR/PACS network are summarized in Table 1. CR capital costs were the average of list prices of two commercial CR systems (FUJI AC3 system; Tokyo, Japan, and Kodak Ektascan CR system; Eastman Kodak, Rochester, NY) capable of handling the anticipated clinical workload. The capital cost of the CR/PACS
Table 1. Capital Costs to Install CR/PACS Network

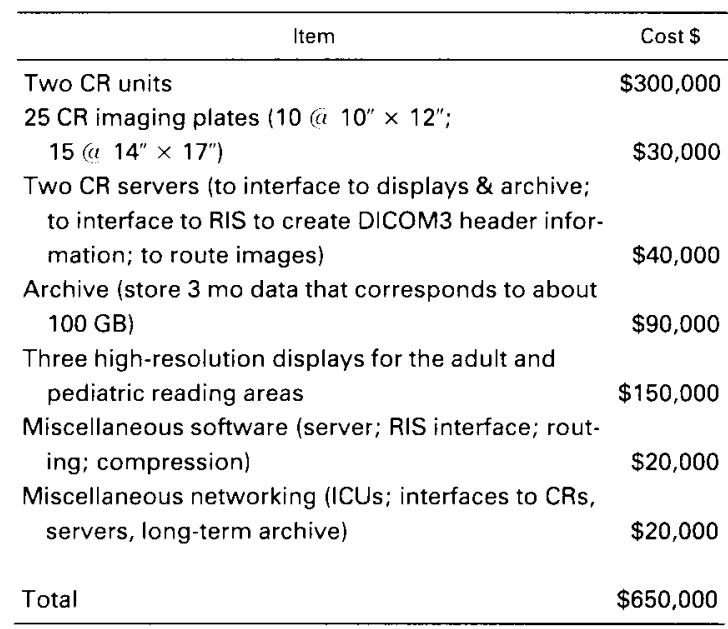

network is estimated to be approximately $\$ 650,000$.

The annual operating costs to maintain this network are summarized in Table 2. Operating costs were taken as an average cost charged by these two vendors for service during normal working hours. The amortized capital costs over a 5 -year period are approximately $\$ 130,000$ per year. The total operating and capital costs of the CR/PACS network is thus estimated to be $\$ 220,000$ per year.

\section{Cost Savings}

The major savings expected from the CR/ PACS network are from supplies (film and chemicals) and staff savings. These are summarized in Table 3. Film list price for a case of 500 films were taken to be $\$ 1,500$ and $\$ 700$ for $14^{\prime \prime} \times$ $17^{\prime \prime}$ and $10^{\prime \prime} \times 12^{\prime \prime}$ film sizes, respectively. The survey of nine film file room clerks, administrators, technologists, and radiologists investigat-

Table 2. Summary of Estimated Annual CR/PACS Network Operating Costs

\begin{tabular}{lc}
\hline \multicolumn{1}{c}{ Item } & Cost $\$$ \\
\hline CR maintenance costs & $\$ 30,000$ \\
$\begin{array}{l}\text { Maintenance on three diagnostic displays }(15 \% \text { of } \\
\text { capital cost) }\end{array}$ & $\$ 27,000$ \\
Archive and server maintenance costs $(10 \%$ of & \\
$\quad$ capital cost & $\$ 13,000$ \\
System manager (0.25 FTE) & $\$ 10,000$ \\
Miscellaneous (optical disks, network upkeep, soft- & \\
$\quad$ ware maintenance) & $\$ 10,000$ \\
Total & $\$ 90,000$ \\
\hline
\end{tabular}


Table 3. Estimated Cost Savings From CR/PACS Network

\begin{tabular}{lc}
\hline \multicolumn{1}{c}{ Item } & Cost Savings $\$$ \\
\hline Film savings $\left(80 \% 14 " \times 17^{\prime \prime} ; 20 \% 10^{\prime \prime} \times 12 " ;\right.$ & \\
$44,000$ films $/ \mathrm{yr})$ & $\$ 118,000$ \\
Chemicals $(7.5 \%$ of film cost) & $\$ 9,000$ \\
.33 Technologist & $\$ 18,000$ \\
1.7 Film library clerks & $\$ 25,000$ \\
Billing for interpreting "lost films" (3\% loss & \\
rate ( $\$$ \$15 per film) & $\$ 20,000$ \\
Miscellaneous (eg, film jackets) & $\$ 10,000$ \\
Total & $\$ 200,000$ \\
\hline
\end{tabular}

ing the potential personnel cost savings showed an average of 1.7 full-time equivalent (FTE) personnel reduction in the film library with a range of $0.5 \mathrm{FTE}$ to $3 \mathrm{FTE}$, and an average of .33 FTE personnel reduction in technologists performing the portable examinations with a range of 0 FTE to 0.5 FTE. Those surveyed indicated that the reduction in the number of file room clerks (approximately 12\%) could be justified by the elimination of portable films. However, it was less clear that a reduction in technologist time would be realized by the introduction of CR. The total estimated cost savings for performing all portable examinations are approximately $\$ 200,000$. This figure is slightly lower than the expected costs of the CR/PACS system of $\$ 220,000$.

\section{DISCUSSION}

Our results correlated with those described by researchers at the University of Alabama in that the total cost of PACS was offset by savings from elimination of film production and management. ${ }^{10}$ The differences in costs associated with our PACS implementation and the one at the University of Alabama are due mainly to the existence of equipment at our site used for ICU teleradiology. The costs associated with the ICU teleradiology system were not explicitly addressed in this study because this system was already in place at Shands. The costs reported in this study for CR systems are lower than those reported in the Alabama study. We used quotations for FUJI AC3 and Kodak Ektascan CR systems, whereas they based their cost analsys on the FUJI AC1 system. The diagnostic workstation costs were approximately the same. We decided to develop the workstation inhouse to meet the needs of our radiologists. It would be difficult to purchase a commercial high-resolution workstation with the capability of ours for $\$ 50,000$ ( 3 for $\$ 150,000$ ). We did not include the cost of acquiring the ICU remote review stations, instead we planned to continue to use the existing image displays in four ICUs that were installed 7 years ago to provide clinicians with digitized images. ${ }^{11}$ The conclusions obtained in this current study are not dependent on the presence of remote review stations in ICUs. A filmless CR/PACS network could eliminate film in the radiology department by replacing light boxes with three highquality digital displays. This would limit access to images by clinicians but is technically feasible and would also eliminate the problem of lost ICU films.

Our analysis is based on elimination of film. It was assumed that the imaging needs would be satisfied by digital displays. From time to time there may be a need to generate a hard copy of images for communication or documentation. Using the PACS, high-resolution images could be printed on a laser camera with one image per film. Intensive care examinations are usually only useful for a short period of time, and a "history" of an event can be made with multiple subsampled images formatted on a single film. In our institution, the use of up to 12 images per film would likely be acceptable for this, as opposed to a diagnostic purpose. Only $10 \%$ of our current film volume would be required to print all ICU portable images using the multiformat model. In addition, it is possible to make hard copies using relatively inexpensive paper printers. ${ }^{12}$

A practical solution to the problem of longterm digital archival is storing images on tape and maintaining a data base to record tape contents. A 4-mm tape drive costs about $\$ 1,800$ with each tape costing about $\$ 12$ and holding between 2 and 5 GByte of uncompressed data. For archiving portable ICU images, lossy compression (10:1 to 20:1) would be acceptable which would give each tape the ability of storing up to 10,000 images. This is an inexpensive solution whose major limitation is the slow and labor intensive method for image retrieval. However, given the very low image retrieval rate expected for portable images, this is not a significant limitation.

One key question pertaining to introducing a 
CR/PACS network is the ability of radiologists to read portable chest radiographs using current software packages and diagnostic displays. The increasing number of facilities that have moved to a filmless environment shows that this is possible to achieve in routine clinical practice. More debatable are the economic aspects of soft-copy displays, which still suffer problems of light output, reliability, and economic efficiency. Uncertainties still exist regarding the specific benefits and limitations of replacing film with current generation soft-copy displays in routine practice, such as reading portable examinations presented in this study. ${ }^{13}$

It is possible that radiologists may require more time to read films from soft copy displays than from the light boxes although experience to date is very limited. The time required to read from soft-copy displays will depend on the speed of image retrieval, software design, and also on radiologist training. However, soft-copy reading may also improve patient diagnosis by use of image processing techniques. Accordingly, any longer reading times may directly correlate with improvements in radiologist performance. These are important issues but at present they are very difficult to quantify and resolve in an objective manner. Accordingly, the cost of the radiologist was excluded from this cost analysis.

This study did not consider the space required to accommodate 44,000 portable images generated each year. Radiographic images need to be stored for a minimum period of time as specified by state regulations, eg, 5 years in Florida. At present, the film library within Shands Hospital's Radiology Department has a storage area of approximately $1,000 \mathrm{ft}^{2}$ and stores images generated within the last 3 months. Images generated within the last 2 years are stored in Shands Hospital's subbasement and occupy a total area of $1,768 \mathrm{ft}^{2}$. Images older than 2 years are subsequently moved to the long-term archive that is difficult to access. Although it is clear that a CR/PACS network would reduce the space requirements for film storage, quantifying this benefit is difficult.

The benefits of decreasing the portable film repeat rate were not shown in this study because repeat rates for portable ICU examinations at Shands Hospital measured over 3 consecutive months were found to be very low $(\sim 3 \%)$. Most repeat radiographs at Shands are caused by positioning errors and the introduction of CR would not significantly reduce the rate of repeat examinations. Our low repeat rate results from good training and documentation of technique factors for long-stay patients and is similar to data reported for another teaching hospital. ${ }^{14}$ However, portable repeat rates can be as high as $12 \%,{ }^{15}$ and facilities with high rates would benefit to a greater extent from a CR/PACS network than the data presented here suggest.

\section{CONCLUSION}

Proponents of PACS anticipate major benefits to be derived from filmless radiology departments. These relate to the elimination of lost films, efficient transmission of images to referring clinicians, convenient archival storage, and improved diagnosis by the use of image processing. ${ }^{9}$ Although such benefits are difficult to quantify, they are the rationale for the move to filmless radiology departments in the United States ${ }^{7,16,17}$ and in Europe. ${ }^{6,18,19}$ An example of the hospital benefit achievable by a CR/PACS network is the speed of delivery of images to an ICU impacting on both patient care and efficiency of ICU staff. This study clearly shows that for a large institution with a substantial portable workload, costs alone are unlikely to inhibit the introduction of a PACS/CR network for performing portable examinations.

\section{ACKNOWLEDGMENT}

The authors gratefully acknowledge Karen Dodge, RT, Walter E. Drane, MD, Beverly A. Hoyle, RT, Gloria Kish, William E. Loeffler, and Jonathan L. Williams, MD, for their useful discussion and assistance in obtaining financial data, and Linda Waters-Funk for manuscript preparation.

\section{REFERENCES}

1. Sonada $\mathbf{M}$, Takano $\mathbf{M}$, Miyahara $\mathbf{J}$, et al: Computed radiography utilizing scanning laser stimulated luminescence. Radiology 148:833-838, 1983

2. Schaefer CM, Prokop M: Storage phosphor radiography of the chest (editorial). Radiology 183:314-315, 1993
3. Sanada S, Doi K, Xu X-W, et al: Comparison of imaging properties of a computed radiography system and screen-film systems. Med Phys 18:414-420, 1991

4. Schaeffer CM, Green RE, Oestmann JW, et al: Improved control of image optical density with low-dose digital 
and conventional radiography in bedside imaging. Radiology 173:713-716, 1989

5. Niklason LT, Chan H-P, Cascade PN, et al: Portable chest imaging: Comparison of storage phosphor digital, asymmetric screen-film, and conventional screen-film systems. Radiology 186:387-393, 1993

6. Greinacher CRC, Semann B: SIENET installations in routine use: Technical commonalities, individual application scenarios, economic facts. SPIE Med Imaging 2165:490500, 1994

7. Smith DV, Smith S, Bender GN, et al: Lessons learned and two years clinical experience in implementing the medical diagnostic imaging support (MDIS) system at Madigan Army Medical Center. SPIE Med Imaging 2165: 538-555, 1994

8. Evens RG: The economic impact of technology on diagnostic imaging at a university medical center. Am J Roentgenol 153:179-183, 1989

9. Straub WH, Gur D: The hidden costs of delayed access to diagnostic imaging information: Impact on PACS implementation. Am J Roentgenol 155:613-616, 1990

10. Tucker DM, Barnes GT, Koehler RE: Picture archiving communication systems in the intensive care unit. Radiology 196:297-304, 1995

11. Gillespy T III, Staab EV, Lawrence E: Electronic imaging in a teaching hospital intensive care unit: evaluation of the Clinical Review System. J Digit Imaging 3:124128,1990
12. Patt R, Freedman M, Steller D, et al: Tests of a new paper display for radiology images. SPIE Med Imaging 2164:210-214, 1994

13. Honeyman JC, Huda W, Palmer CK, et al: Evaluation of a high resolution workstation for diagnostic interpretation of portable radiographs. SPIE Med Imaging 2431:530537,1995

14. Marglin SI, Rowberg AH, Godwin JD: Preliminary experience with portable digital imaging for intensive care radiography. J Thorac Imag 5:49-54, 1990

15. Wandke JC: Bedside chest radiography. Radiology 190:1-10, 1994

16. Friedenberg RM: Potential clinical problems associated with PACS. Radiology 189:55A-57A, 1993

17. Siegel EL: The transition to the filmless imaging department: Early experience at the Baltimore VA Hospital, in Boehme JM, Rowberg AH, Wolfman NT (eds): SCAR Proceedings, Carlsbad, CA, Symposia Foundation 5 , 1995 (abstr)

18. Bryan S, Weatherburn G, Taylor J, et al: Evaluation of PACS at Hammersmith Hospital: Assessment of radiology department performance in the intensive care unit. SPIE Med Imaging 1899:434-440, 1993

19. Mosser H, Urban M, Partan G, et al: Clinical routine operation of a filmless radiology department: 20 months experience, in Boehme JM, Rowber AH, Wolfman NT (eds): SCAR Proceedings, Carlsbad, CA, Symposia Foundation 30-38, 1994 